\title{
Comparison of predator-parasitoid-prey interaction models for different host plant qualities
}

\author{
C. Sanchez 1 , M. Gamez 2,5 , F. J. Burguillo ${ }^{3}$ J. Garay ${ }^{4}$ and T. Cabello ${ }^{1}$ \\ IDepartment of Biology and Geology, University of Almeria, Almeria, Spain \\ ${ }^{2}$ Department of Mathematics, University of Almeria, Almeria, Spain \\ ${ }^{3}$ Department of Physical Chemistry, University of Salamanca, Salamanca, Spain \\ ${ }^{4}$ MTA Centre for Ecological Research, Evolutionary Systems Research Group, Hungary \\ ${ }^{5}$ Corresponding author.E-mail:mgamez@ual.es
}

Keywords: Bemisia tabaci, Cultivar, Lotka-Volterra model, Nesidiocoris tenuis, Phytophagous-parasitoid-predator system, Trichogramma achaeae.

\begin{abstract}
Population dynamics models suggest that the over-all level of resource productivity plays an important role in community dynamics. One such factor of resource productivity is the quality of the host plant, which can determine the effectiveness of entomophagous (predatory and parasitoid) species by altering the growth rate of the phytophagous population via effects on fecundity, survival, and rate of development. These effects have been studied in relation to the distribution of host plants and their physiological state. However, few studies have considered the differences among plant cultivars. The objective of this study was to identify a continuous-time dynamic model, to describe the effects of different tomato cultivars on a one predatortwo prey model. The experiment was carried out under greenhouse conditions using ten tomato cultivars, with the predatory species Nesidiocoris tenuis (Reuter) (Insecta, Hemiptera, Miridae) and two prey species: the phytophagous species Bemisia tabaci (Gennadius) (Insecta, Hemiptera, Aleyrodidae) and the parasitoid species Trichogramma achaeae (Nagaraja \& Nagarkatti) (Insecta, Hymenoptera, Trichogrammatidae); the latter was used as the intraguild-prey. Using the software SIMFIT, we found that a three-dimensional Lotka-Volterra type system could be well fitted to the data, estimating the phytophagous species' growth rate, the parasitoid and predator mortality rates, the predation and parasitism rates, and the parasitoid emergence rate according to the cultivar type. The results showed an important effect of the host plant quality, by cultivar, on intraguild predation, resulting in important changes in the dynamics of phytophagous populations. These results are also discussed in relation to their importance in the biological control of pest species in greenhouse crops.
\end{abstract}

\section{Introduction}

Biological control programmes in European greenhouse tomato crops depend on the use of Nesidiocoris tenuis (Reuter) or Macrolophus pygmaeus (Hem.: Miridae) to control the sweet potato whitefly, Bemisia tabaci (Gennadius) (Hem.: Aleyrodidae) (Castañe et al. 2004, Calvo et al. 2012) and on Trichogramma achaeae (Nagaraja and Nagarkatti) to control the South American tomato moth, Tuta absoluta (Meyrick) (Lep.: Gelechiidae) (Cabello et al. 2012, Oliveira et al. 2017).

N. tenuis is an omnivorous predator (Sanchez 2008), and T. achaeae is a parasitoid species that attacks lepidopteran eggs (Cabello et al. 2009, Polaszek et al. 2012). Thus, for tomato crops in greenhouses, an important intraguild predation (IGP), exists with $N$. tenuis as the IG-predator and immature stages of $T$. achaeae, inside the host eggs, as the IG-prey (Cabello et al. 2015). It should be noted that the use of different entomophagous species in greenhouse biological control programmes is relatively common (Vila and Cabello 2014). This can lead to direct or indirect interactions such as apparent competition, IGP and resource competition (Janssen et al. 1998). These interactions can have a global impact on the ef- ficiency of biological control agents (Yano 2005, Messelink et al. 2013). Interest in these interactions has resulted in a significant amount of both theoretical and applied research. However, studies that show the impact of IGP in biological control are limited (Janssen et al. 1998, Rosenheim and Harmon 2006).

Evaluation of the efficiency of biological control agents - under IGP conditions - is difficult. Dynamic mathematical Lotka-Volterra type models have been proposed and used for this purpose (Holt and Polis 1997, Berryman 2004, Varga et al. 2010, Gallego et al. 2013).

Mathematical models applied to natural enemies have developed extensively over (the past 90 years), from primarily theoretical works, to more recent applied practices (Hawkins and Cornell, 2004).

The objective of this study was to find a continuous-time dynamic model, to describe the effects of different tomato cultivars on a one predator-two prey model.

This objective is being realized in collaboration with industrial producers of biological agents, since both the selection and use of the agent are relevant to applications by farmers and agronomists. 


\section{Material and methods}

\subsection{Biological material}

T. achaeae was reared at the Applied Entomology Laboratory at the University of Almería (Spain) for 20 generations before the trial. This species was reared using the factitious host Ephestia kuehniella Zeller (Lep.: Pyralidae) in plastic containers ( 1 litre) following the methodology used by Cabello (1985). For that purpose, 12,500 E. kuehniella eggs (irradiated with ultraviolet light) were added to a piece of cardboard $(13 \mathrm{~cm} \times 10.5 \mathrm{~cm})$ and placed in each container. Later, parasitoid adults at a ratio of 1:4 were introduced. The environmental conditions for the growth of the parasitoid were $25 \pm 1^{\circ} \mathrm{C}$, at $60-80 \%$ relative humidity $(\mathrm{RH})$ with a photoperiod 16:9h (L:D). N. tenuis adults were provided by Nesicontrol ${ }^{\circledR}$ (Agrobio, La Mojonera, Almería, Spain). The E. kuehniella irradiated eggs were provided by Biotop (Valbonne, France). The eggs were refrigerated at $7^{\circ} \mathrm{C}$ to preserve them, until their use for both rearing the parasitoids and the greenhouse trial. Finally, B. tabaci adults were provided, by Koppert Biological Systems S.L. (Águilas, Murcia, Spain).

\subsection{Experimental design}

The experiment was designed random complete blocks with four repetitions and one factor (tomato cultivar) as the treatment (to 10 levels).

The trial was conducted from April to June 2015 in an experimental multitunnel greenhouse, with a $4,896 \mathrm{~m}^{2}$ surface area in the TECNOVA Technology Centre (Viator, Almería, Spain). Four isolated modules $(15 \mathrm{~m} \times 8 \mathrm{~m})$ were built in the greenhouse using plastic film $(1.0 \mathrm{~mm} \times 0.5 \mathrm{~mm})$. Each of these modules corresponded to one blocks in the trial design. Each module was divided into 10 plots $\left(12 \mathrm{~m}^{2}\right)$. On April $7^{\text {th }}, 18$ of the following seedling cultivars were transplanted into each plots: Bronco ${ }^{\circledR}$, and Pasadena ${ }^{\circledR}$ (Ramiro Arnedo S.A., Almería, Spain); Creativo ${ }^{\circledR}$, and Genio ${ }^{\circledR}$ (Hm.Clause Ibérica S.A., Almería, Spain); Montenegro ${ }^{\circledR}$, and Ramyle ${ }^{\circledR}$ (Rijk Zwaan Ibérica S.A, Almería, Spain); Byelsa ${ }^{\circledR}$ (Semillas Fitó S.A., Almería, Spain); Caniles ${ }^{\circledR}$ (Zeraim Ibérica S.A., Almería, Spain); Rebelión ${ }^{\circledR}$ (Vilmorin Ibérica S.A., Almería, Spain); and Vernal ${ }^{\circledR}$ (Enza Zaden Investigation Centre S.L.U). Commercial crop management was used in the area, with an exception where no pesticide treatment was used.

All plots were artificially infested with the pest species, B. tabaci, on April $8^{\text {th }}$ (1 day after transplanting, DAT) and April $15^{\text {th }}$ (8 DAT), at a dose of 30 adults $/ \mathrm{m}^{2}$. The natural enemies were released as follows: one release of $N$. tenuis on April 23rd (16 DAT) at a dose of 4 adults $/ \mathrm{m}^{2}$, and 4 releases of the parasitoid T. achaeae 241 parasitized eggs $/ \mathrm{m}^{2}$ every fifteen days, beginning on April 14th (17 DAT).

\subsection{Sampling}

Sampling was conducted every two weeks, a total of 5 times, beginning May $8^{\text {th }}$ (31 DAT) for the pest species $B$. tabaci (nymph stage) and for the predator species $N$. tenuis (adult stage). For this purpose 4 plants were randomly chosen and the 10 last apical leaves of each plant were visually examined, for the number of pest species nymphs and predator adults. The 4 randomly chosen plants in each block and plot were used in subsequent samplings. The parasitoid T. achaeae was evaluated through the sentinel eggs method. To accomplish this, 4 cardboard pieces were placed in each block and plot, using the same plants sampled for $N$. tenuis and $B$. tabaci, to which we had added approximately 200 irradiated E. kuehniella eggs. This sampling was also conducted every two weeks, a total of 4 times, starting on May $7^{\text {th }}$ (30 DAT). The eggs were exposed for 7 days in the greenhouse. They were later taken to the laboratory, and preserved at $25^{\circ} \mathrm{C}$ for an additional 7 days prior to quantification of eggs parasitized by $T$. achaeae. The phenological development of the plants during the trial period was also evaluated.

\subsection{Data analysis}

The number of $B$. tabaci nymphs, $N$. tenuis adults, and parasitized eggs for each sampling event were initially expressed in square metre values. Later, those data were expressed as insect-day accumulated values (IDA). This index, proposed by Ruppel (1983), was applied to evaluate the total impact of pests at a given period of time. IDA data were analysed with GLM univariate analysis for the cultivar factor. Analyses were conducted using IBM SPSS 23 statistical software (IBM 2014).

\subsection{Mathematical model}

Figure 1 shows the network interactions used in our model according to the nomenclature applied by Mills (2006). Its mathematical expression is shown below:

$$
\begin{array}{ll}
\text { Pest species } & x_{1}{ }^{\prime}=x_{1}\left(m_{1}-\alpha \cdot x_{1}-\gamma_{1} \cdot x_{3}\right) \\
\text { Parasitoid species } & x_{2}{ }^{\prime}=x_{2}\left(m_{2}-\gamma_{2} \cdot x_{3}\right) \\
\text { Predator species } & x_{3}{ }^{\prime}=x_{3}\left(-m_{3}+\bar{\gamma}_{1} \cdot x_{1}+\bar{\gamma}_{2} \cdot x_{2}\right)
\end{array}
$$

where $x_{1}, x_{2}$, and $x_{3}$ are the densities (number $/ \mathrm{m}^{2}$ ) of pest (phytophagous), parasitoid and predator species, respectively. According to the terminology of Abrams (2012), $m_{1}$ is the intrinsic growth rate of the pest (prey 1); $m_{2}$ is the increase rate of the parasitoid species (prey 2), due to the intrinsic growth rate and releasing rate; $m_{3}$ is the death rate of the predator in the absence of prey; $\alpha$ is the coefficient of intraspecific competition for pest species; $\gamma_{1}$ and $\gamma_{2}$ are the slopes of the predator's functional response when they kill the pest species (prey 1) and the parasitoid species (prey 2), respectively; and $\bar{\gamma}_{1}$ and $\bar{\gamma}_{2}$ are the slopes of the predator's numerical response when they kill and eat the pest species (prey 1) or the parasitoid species (prey 2), respectively.

Using the statistical software SIMFIT version 2017 (Bardsley 2017), the system of equations (1) was fitted to the data corresponding to the number of $N$. tenuis adults, $B$. ta- 


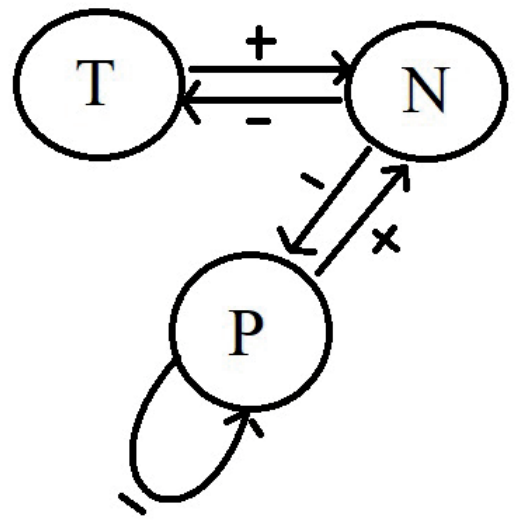

Figure 1. Network of interactions considered in the model phytofagous - parasitoid - predator $(\mathrm{P}=$ pest Bemisia tabaci $; \mathrm{T}=$ parasitoid Trichogramma achaeae and $\mathrm{N}=$ predator Nesidiocoris tenuis); the linking arrows show benefits $(+)$ and losses (-).

baci nymphs, and immature stages of $T$. achaeae per square metre in each sampling event for the three variables used: Byelsa, Caniles and Rebelion.

\subsection{Optimal control of the system}

Based on (1), we consider the control system

$x^{\prime}=F\left(x_{1}, x_{2}, x_{3}, u\right)=\left(\begin{array}{c}x_{1}\left(m_{1}-\alpha \cdot x_{1}-\gamma_{1} \cdot x_{3}\right) \\ x_{2}\left(m_{2}-\gamma_{2} \cdot x_{3}\right)+u \\ x_{3}\left(-m_{3}+\bar{\gamma}_{1} \cdot x_{1}+\bar{\gamma}_{2} \cdot x_{2}\right)\end{array}\right)$

where control function $u$ describes the time-dependent rate of release of parasitoids, realizing that the biological control of the pest $T$. absoluta is not considered in this model. Fix a time interval $\left[t_{1}, t_{2}\right]$, and for each $\varepsilon>0$, let $U_{\varepsilon}\left[t_{1}, t_{2}\right]$ be the set of piece-wise constant, $\varepsilon$-small controls $0 \leq u(t) \leq \varepsilon$ $\left(t \in\left[t_{1}, t_{2}\right]\right)$.

In order to keep the pest above a level $K$, minimizing the total release of agent, we have to solve the following optimal control problem:

$\Psi(u)=\int_{t_{1}}^{t_{2}} c u(t) d t \rightarrow \min$,

$u \in U_{\varepsilon}\left[t_{1}, t_{2}\right]$

$\dot{x}=F\left(x_{1}, x_{2}, x_{3}, u\right), \rightarrow x(0)=x^{0}$

$g\left(x_{1}(t) x_{2}(t) x_{3}(t) \geq 0 \quad\left(t \in\left[t_{1}, t_{2}\right]\right.\right.$

where function $g\left(x_{1}, x_{2}, x_{3}\right)=x_{2}-K$ measures the level of the parasitoid, in comparison to a threshold value, below which the parasitoid cannot control the pest T. absoluta. For the solution, the toolbox developed for MatLab by Banga et al. (2005) and Hirmajer et al. (2009) was applied.

\section{Results}

\subsection{Effects of cultivars on populations of the three species}

The cultivar was observed to have a significant effect on the $N$. tenuis predator's IDA for the pest species $B$. tabaci and the parasitoid species $T$. achaeae $(\mathrm{F}=6.268, \mathrm{df}=9 / 150, \mathrm{P}<$ $0.01 ; \mathrm{F}=8.589, \mathrm{df}=9 / 150, \mathrm{P}<0.01 ; \mathrm{F}=8.263, \mathrm{df}=9 / 150$, $\mathrm{P}<0.01$, respectively) (Fig. 2). In Figure 2A, all the predator IDA values were relatively high and did not differ significantly, except for the cultivar Rebelion. The pest species had the lowest IDA values (Fig. 2B) for the following three cultivars: Ramyle, Byelsa and Pasadena. Meanwhile, cultivar Rebelion showed the highest incidence of the pest species, and the remaining cultivars had intermediate IDA values. Finally, Figure 2C shows that the cultivar Byelsa exhibited the lowest incidence of the immature stages of the parasitoid, whose values differed significantly from those corresponding to the Bronco, Rebelion and Caniles cultivars.

\subsection{Population dynamic models}

From the 10 cultivars previously evaluated, we selected Byelsa and Rebelion, which exhibited more extreme values of incidence regarding phytophagous species, predator, and parasitoid, and Caniles, a cultivar with an intermediate value.

Mathematical model (1) was well-fitted to the data for cultivars Byelsa and Caniles, but not to Rebelion, as shown in the corresponding curves in Figure 3. From this, we can conclude that the plants corresponding to the cultivar Rebelion presented a very low predator incidence, indicating that it had some impact on the pest species population, but not on the parasitoid population.

Caniles (Fig. 3B) has very similar values to those of Byelsa and fits the model. However, the population of $T$. achaeae decreases due to intraguild predation before the value of B. tabaci (prey 1) declines.

Finally, Rebelion could not be adjusted to our model. In this case, the predator population was very small, thus there was no effect on the T. achaeae population.

\subsection{Solution of the optimal control problem}

Based on the previous results, we conclude that the predator $N$. tenuis (adult stage) is necessary for the control of the pest species $B$. tabaci (nymph stage), but has adverse side effects on the immature stages of the parasitoid $T$. achaeae used for the control of a different pest species, T. absoluta, not considered in the model. From a theoretical point of view, we had the following question: How should the release rate of the parasitoid increase to maintain sufficient control of the pest $T$. absoluta? For that purpose, and based on previously published studies (e.g., Cabello et al. 2012, 2015), we determined that an appropriate density of parasitoids (immature stages) within crop plots was 100 individuals per square metre. Values lower than this density can cause damage due to the pest species T. absoluta (Fig. 4A). The results (Fig. 4B) 

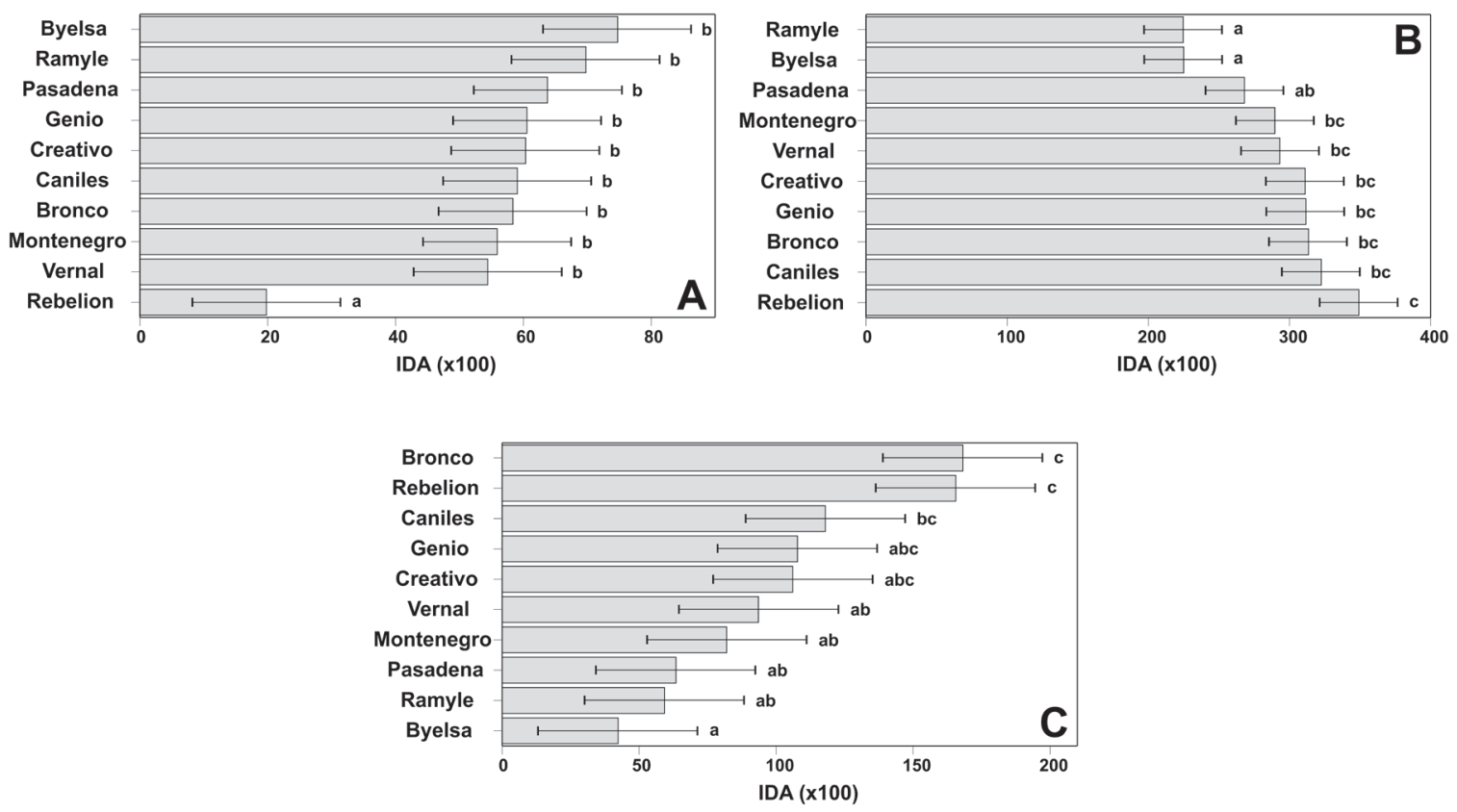

Figure 2. Averages of insect-day accumulated (IDA) for Nesidiocoris tenuis adults (A), Bemisia tabaci nymphs (B), and immature stages of Trichogramma achaeae (C) in greenhouse tomato crops by cultivar (whiskers represent SE). : (Values for the entomophagous, in (A) and (C) with decreasing, for the pest, in (B) with increasing incidence.)
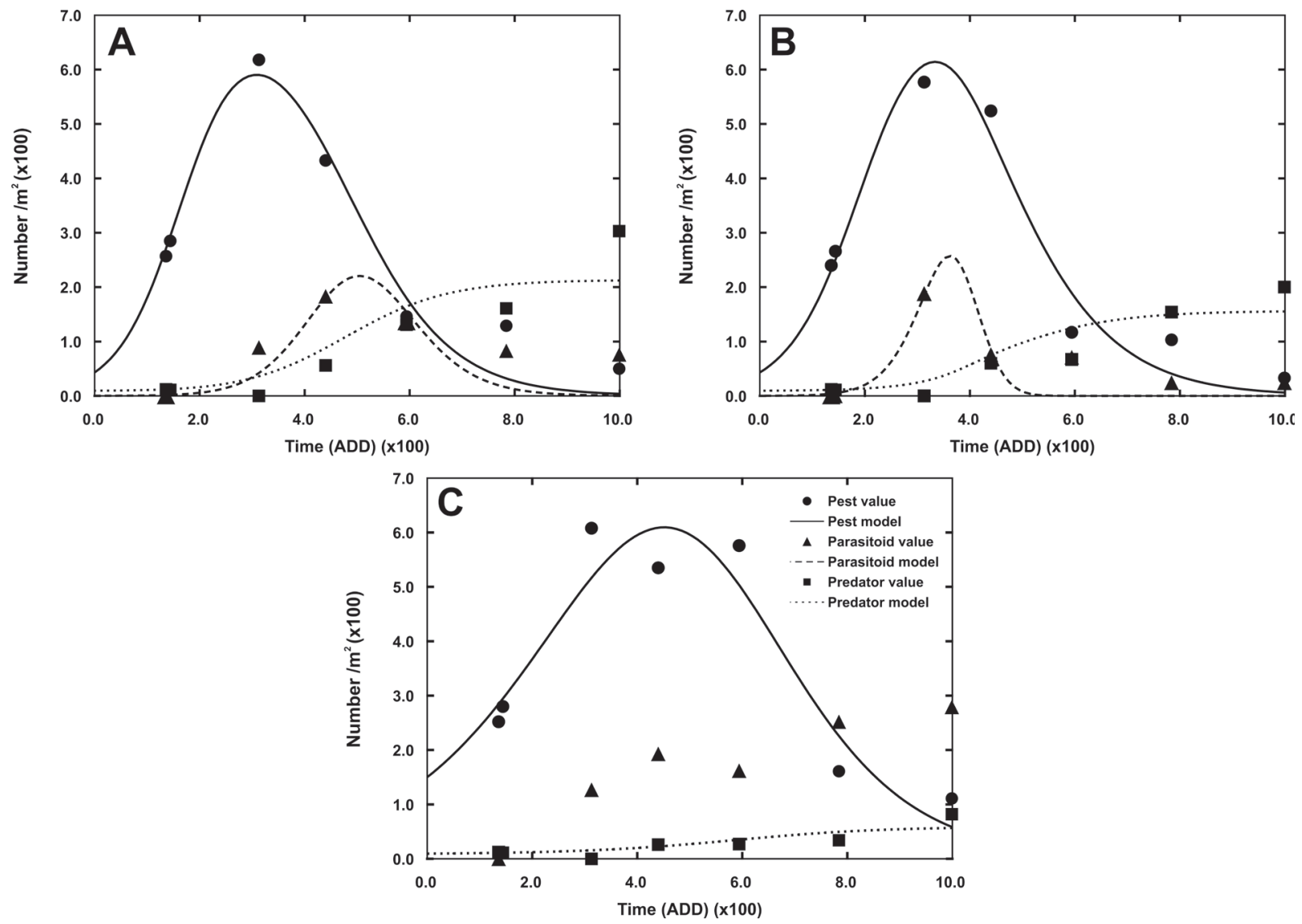

Figure 3. Densities obtained from the fitted model: prey species $=$ Bemisia tabaci (nymph stage), parasitoid species $=$ Trichogramma achaeae, and predatory species $=$ Nesidiocoris tenuis, in greenhouse tomato crop for the cultivars: Byelsa (A), Caniles (B), and Rebelion (C). ADD stands for Accumulated Degree Days. 

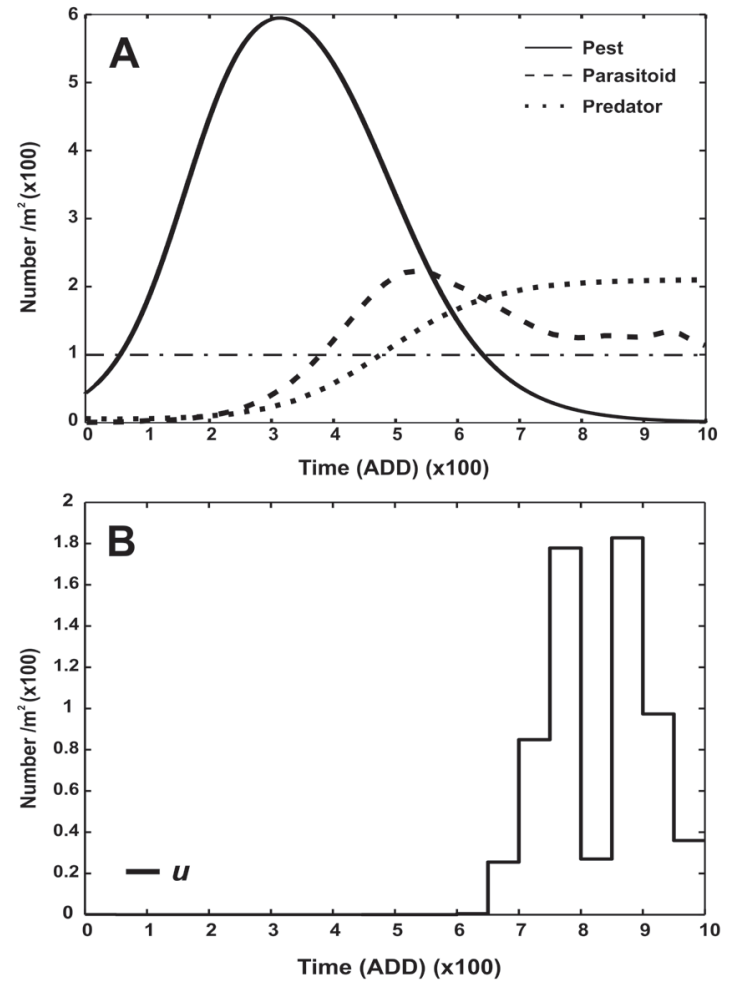

Figure 4. For $\left[t_{1}, t_{2}\right]=[4,10]$, the optimal trajectory $(A)$ and control of the problem (B) for the two-prey-one-predator model using greenhouse tomato crop data for the Byelsa cultivar. $u$ is the rate of release of parasitoids.

show that, to maintain the afore mentioned threshold value, it is necessary to carry out 7 additional releases in the crop cycle, for an overall density of 80 specimens $/ \mathrm{m}^{2}$.

\subsection{Stable coexistence of the population system. A theoretical point of view}

As outlined in the previous section, for the considered species, an optimal release of the parasitoid can be obtained by solving an optimal control problem, which also guarantees that the parasitoid population remains above a desired level. Nevertheless, if there is a stable coexistence (i.e., an asymptotically stable positive equilibrium) and the equilibrium value of the parasitoid, $x_{2}^{*}$, is greater than the given threshold $K$, the desired level can be asymptotically reached without any further release. If the convergence is rapid enough, $x_{2}(t)>K$ can be reached very quickly, as shown in Figure 5 obtained with illustrative parameter values.

First, we find a necessary and sufficient condition for the existence of a positive equilibrium of system (1). To this end, we define function $f: R^{3} \rightarrow R^{3}$,

$$
f\left(x_{1}, x_{2}, x_{3}\right)=\left(\begin{array}{c}
x_{1}\left(m_{1}-\alpha \cdot x_{1}-\gamma_{1} \cdot x_{3}\right) \\
x_{2}\left(m_{2}-\gamma_{2} \cdot x_{3}\right) \\
x_{3}\left(-m_{3}+\bar{\gamma}_{1} \cdot x_{1}+\bar{\gamma}_{2} \cdot x_{2}\right)
\end{array}\right) .
$$

Then, a nonzero vector $x^{*} \in R^{3}$ represents equilibrium for the considered dynamics if and only if $f\left(x^{*}\right)=0$. The unique solution of this equation is easily obtained:

$$
\begin{gathered}
x_{1}^{*}=\frac{m_{1} \gamma_{2}-m_{2} \gamma_{1}}{\alpha \gamma_{2}}, \\
x_{2}^{*}=\frac{m_{3} \alpha \gamma_{2}-\bar{\gamma}_{1}\left(m_{1} \gamma_{2}-m_{2} \gamma_{1}\right)}{\alpha \gamma_{2} \bar{\gamma}_{2}}, \\
x_{3}^{*}=\frac{m_{2}}{\gamma_{2}} .
\end{gathered}
$$

Thus, a necessary and sufficient condition for $x^{*}>0$ is

$$
\frac{m_{3} \alpha \gamma_{2}}{\bar{\gamma}_{1}}>m_{1} \gamma_{2}-m_{2} \gamma_{1}>0
$$

To analyse the stability of system (1), we calculate the Jacobian

$A=f^{\prime}\left(x^{*}\right)=\left(\begin{array}{ccc}-\alpha x_{1}^{*} & 0 & -\gamma_{1} x_{1}^{*} \\ 0 & 0 & -\gamma_{2} x_{2}^{*} \\ \bar{\gamma}_{1} x_{3}^{*} & \bar{\gamma}_{2} x_{3}^{*} & 0\end{array}\right)$

the characteristic polynomial of which is

$\lambda^{3}+\alpha x_{1}^{*} \lambda^{2}+\left(\gamma_{1} \bar{\gamma}_{1} x_{1}^{*}+\gamma_{2} \bar{\gamma}_{2} x_{2}^{*}\right) x_{3}^{*} \lambda+\alpha \gamma_{2} \bar{\gamma}_{2} x_{1}^{*} x_{2}^{*} x_{3}^{*}=0$

Hence, by the Routh-Hurwitz criterion (see e.g., Chen et al. 2004 ), for the asymptotic stability of equilibrium $x^{*}$ it is enough to see that

$$
\alpha x_{1}^{*}\left(\gamma_{1} \bar{\gamma}_{1} x_{1}^{*}+\gamma_{2} \bar{\gamma}_{2} x_{2}^{*}\right) x_{3}^{*}>\alpha \gamma_{2} \bar{\gamma}_{2} x_{1}^{*} x_{2}^{*} x_{3}^{*}
$$

which always holds whenever equilibrium $x^{*}$ is positive. We can conclude that condition (3) implies stable coexistence in the pest-parasitoid-predator system (1).

It is easy to confirm that for the parameter values obtained in Table 1, the sufficient conditions (3) for the stable coexistence are not satisfied. Nevertheless, the following example shows that the pest-parasitoid-predator system (1) with appropriate biological parameters display stable coexistence, and the parasitoid density even without control reaches the required density rather quickly.

Example. Consider the parameter system $m_{1}=1.54 ; m_{2}$ $=1.73 ; m_{3}=0.1 ; \alpha=0.23 ; \gamma_{1}=1.14 ; \gamma_{2}=1.39 ; \bar{\gamma}_{1}=0.16$ and $\bar{\gamma}_{2}=0.02$. A simple calculation shows that these parameters satisfy condition (3), therefore, system (1) has an asymptotically stable equilibrium $x^{*}=(0.527,0.797,1.245)$. The Jacobian 
Table 1. Fitting of the two-prey- one-predator model to the greenhouse tomato crop data for Byelsa and Caniles cultivars.

\begin{tabular}{|c|c|c|c|c|c|c|c|c|c|c|c|}
\hline \multirow{2}{*}{ Cultivar } & \multicolumn{8}{|c|}{ Fitting parameters (average \pm SE) } & \multicolumn{3}{|c|}{ Statistical parameters } \\
\hline & $m_{1}$ & $\mathrm{~m}_{2}$ & $m_{3}$ & $\alpha$ & $\gamma_{1}$ & $\gamma_{2}$ & $\bar{\gamma}_{1}$ & $\bar{\gamma}_{2}$ & d.f. & $r^{2}$ & $P$ \\
\hline \multirow[b]{2}{*}{ Byelsa } & 1.785 & 2.222 & $710^{-4}$ & 0.224 & 1.318 & 1.811 & 0.131 & $210^{-4}$ & & & \\
\hline & $( \pm 0.166)$ & $( \pm 0.15)$ & $( \pm 0.256)$ & $( \pm 0.04)$ & $( \pm 0.214)$ & $( \pm 0.439)$ & $( \pm 0.011)$ & $( \pm 0.211)$ & 13 & 0.976 & $<0.05$ \\
\hline \multirow[b]{2}{*}{ Caniles } & 1.605 & 3.584 & $710^{-4}$ & 0.178 & 1.602 & 8.654 & 0.097 & 0.120 & & & \\
\hline & $( \pm 0.140)$ & $( \pm 0.284)$ & $( \pm 0.164)$ & $( \pm 0.032)$ & $( \pm 0.293)$ & $( \pm 1.841)$ & $( \pm 0.011)$ & $( \pm 0.049)$ & 13 & 0.952 & $<0.05$ \\
\hline
\end{tabular}

$$
A:=f^{\prime}\left(x^{*}\right)=\left(\begin{array}{ccc}
-0.12 & 0 & -0.6 \\
0 & 0 & -1.09 \\
0.2 & 0.02 & 0
\end{array}\right)
$$

has eigenvalues $\lambda_{1}=-0.0492+0.3770 \mathrm{i}, \lambda_{2}=-0.0492$ $0.3770 \mathrm{i}$, and $\lambda_{3}=-0.0228$, all with negative real parts. Thus, the solutions tend towards a positive equilibrium, as demonstrated by the simulation results plotted in Figure 5. Setting $K=0.6$, we can see that parasitoid density $x_{2}(t)$ exceeds the threshold $K$. We note that, by a slight modification of the optimal control model (2), the system could also be controlled along a prescribed trajectory.

\section{Discussion}

Plants have developed different defence mechanisms against the phytophagous organisms that prey on them (e.g., Smith 2005). However, this also has an impact on subsequent trophic levels, such as predators and parasitoids (e.g., Price et al. 1980). All of this is related to the different botanical species and their effects on both phytophagous and entomophagous organisms. However, few studies have investigated the differences among different cultivars from the same botanical species. Variations between cultivars can play an important role in the activity and efficiency of entomophagous agents (Bergman and Tingey 1979) as discussed by Bottrell et al. (1998), though questions remain, especially with respect to multitrophic effects involving complex interactions.

Our results demonstrating the effects of tomato cultivars on biological activity, especially on $N$. tenuis and, to a lesser extent, on T. achaeae, are supported by previous studies (e.g., Cabello et al. 2012, Vila et al. 2012). Thus, our results corroborate these findings.

Additionally, mathematical models similar to those shown here have been used to evaluate the efficacies of different species of Trichogramma in greenhouse tomatoes (e.g., Gallego et al. 2013). This demonstrates the commercial usefulness of these mathematical models in the biological control of pest species.

Notably, the studies carried out to elucidate the IGP in greenhouse tomato crops with a two-prey-one-predator model, specifically with the species $N$. tenuis, T. achaeae and $T$. absoluta, reveal the detrimental effects of the predator on the activity of the parasitoid and its resulting control of the pest prey T. absoluta (Gallego et al. 2013). The innovation of the present results is that they highlight that when the predator N.tenuis is used for the biological control on a pest species
Figure 5. Solution of system (1) with initial value $\mathrm{x}(0)=(0.7,0.4,1.0)$, and $x_{2}$ exceeding the threshold value $K=$ 0.6 from time $\mathrm{t}_{0}$.

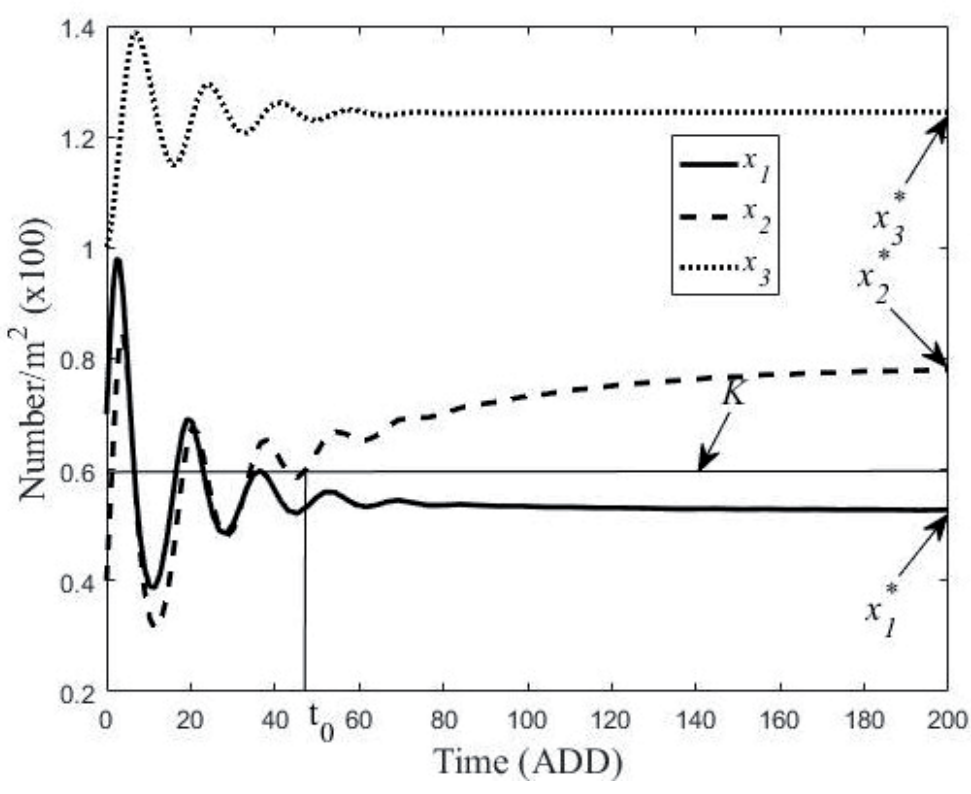


B. tabaci, different from the one than controls biologically $T$. achaeae, these detrimental effects are also produced.

Our results are unique because they modify existing models to study the varietal effects of both natural enemies. These effects can determine the efficiency of the generalist programmes of biological control at a practical level.

Further, this mathematical approach makes it possible to minimize the cost of applying agents, emphasizing the importance of the proposed optimal control model in integrated pest management (IPM) and/or biological control programmes.

\section{Conclusions}

The impact and efficiency of biological control programmes on pest species in greenhouse crops, in which various natural enemies are used during the crop cycle, can be influenced by the use of cultivars. The optimal control model introduced here contributes to the methodological development of the biological control of pests in greenhouse crops.

This mathematical approach also makes it possible to minimize the cost of the application of agents, demonstrating the importance of the proposed optimal control model in integrated pest management (IPM).

Based on previous studies, this is the first example of an experiment-based mathematical model that represents this type of intraguild predation (IGP). In this sense it should be noted that in recent decades the optimization of chemical control of pests has been widely developed, both from a theoretical and applied points of view (see Poston et al., 1983, Mumford and Norton 1984, Pedigo et al. 1986). However, this optimization of chemical control, on the one hand, presents problems of application (e.g., Saphores 2000) and, on the other, it is not applicable in the biological control of pests (e.g., Shoemaker 1973); fundamentally because this optimization is related with the cost of the use of pesticides. Furthermore, this optimization deals with a short-term solution, and not with the long-term solution by biological control of pests. Solutions were sought, from a theoretical point of view, to the problem of the non-applicability of the optimization developed for chemical control, to biological control (e.g., Tang and Cheke 2008, Tang et al., 2010). For all these reasons, it is considered that, from a practical point of view, the developed method could be the foundations for the decision making in the biological control of pests, when several entomophagous species are involved at the same time.

\section{References}

Abrams, P.A. 2012. Predator-prey models. In: Hastings, A. and Gross, L. (eds.), Encyclopedia of Theoretical Ecology. University of California Press, Berkeley, USA. pp. 587-594.

Banga, J.R., Balsa-Canto, E., Moles, C.G. and Alonso, A.A. 2005 Dynamic optimization of bioprocesses: efficient and robust numerical strategies. J. Biotechnol. 117:407-419.

Bardsley W.G. (2017) "SIMFIT statistical package", version 7.3.0. http://www.simfit.org.uk.
Bergman, J.M and Tingey, W.M. 1979. Aspects of interaction between plant genotypes and biological control. Bull. Entomol. Soc. Am. 25:275-279.

Berryman, A.A. 2004. The theoretical foundations of biological control. In: Hawkins, B.A. and Cornell, H.V. (eds.), Theoretical Approaches to Biological Control. Cambridge University Press, Cambridge, UK. pp. 3-21.

Bottrell, D.G., Barbosa, P. and Gould, F. 1998. Manipulating natura enemies by plant variety selection and modification: A realistic strategy? Annu. Rev. Entomol. 43:347-367.

Cabello, T. 1985. Especies de Trichogramma (Hym.: Trichogrammatidae) parasitas de Heliothis armígera (Lep.: Noctuidae) en Andalucia. Ph.D. Diss., Universidad de Cordoba, Cordoba, ES.

Cabello, T., Bonfil, F., Gallego, J.R., Fernandez, F.J., Gamez, M. and Garay, J. 2015. Can interactions between and omnivorous hemipteran and an egg parasitoid limit the level of biological control for the tomato pinworm? Environ. Entomol. 44:12-26.

Cabello, T., Gallego, J.R., Vila, E., Soler, A., Pino del M., Carnero, A., Hernandez-Suarez, E. and Polaszek, A. 2009. Biological control of the South American tomato pinworm, Tuta absoluta (Lep.: Gelechiidae), with releases of Trichogramma achaeae (Hym.: Trichogrammatidae) in tomato greenhouses of Spain. IOBC WPRS Bull. 49:225-230.

Cabello, T., Gallego, J.R., Fernandez, F.J., Gamez, M., Vila, E., Pino, M. and Hernandez, E. 2012. Biological control strategies for the South American tomato moth in greenhouse tomatoes. J. Econ. Entomol. 105:2085-2096.

Calvo, F.J., Bolckmans, K. and Belda, J.E. 2012. Release rate for a pre-plant application of Nesidiocoris tenuis for Bemisia tabaci control in tomato. BioControl 57:809-817.

Castañe, C., Alomar, O., Goula, M. and Gabarra, R. 2004 Colonization of tomato greenhouses by the predatory mirid bugs Macrolophus caliginosus and Dicyphus tamaninii. Biol. Control 30:591-597.

Chen, B.M., Lin, Z. and Shamesh, Y. 2004. Linear Systems Theory. A Structural Decomposition Approach. Birkhauser, Boston.

Gallego, J.R., Lopez, I., Gamez, M., Cabello, T., Varga, Z. and Garay, J. 2013. Simulation model applied to biological pest control by entomophagous species in commercial tomato greenhouses. Hung. Agric. Eng. 25:67-70.

Hawkins, B. A. and Cornell, H.V. (eds.) 2004. Theoretical Approaches to Biological Control. Cambridge Univ. Press, Cambridge, UK.

Hirmajer, T., Balsa-Canto, E. and Banga, J. 2009. DOTcvpSB, a software toolbox for dynamic optimization in systems biology. BMC Bioinformatics 10:199.

Holt, R.D. and Polis, G.A. 1997. A theoretical framework for intraguild predation. Am. Nat. 149:745-764.

IBM. 2014. IBM SPSS Statistics for Windows, Version 23.0 IBM Corp. Armonk, IBM Corp., NY.

Janssen, A., Pallini, A., Venzon, M and Sabelis, M.W. 1998. Behaviour and indirect interactions in food webs of plant-inhabiting arthropods. Exp. Appl. Acarol. 22:497-521.

Messelink, J.G., Bloemhard, C.M.J., Sabelis, M.W. and Janssen, A 2013. Biological control of aphids in the presence of thrips and their enemies. BioControl 58:45-55.

Mills, N. 2006. Interspecific competition among natural enemies and single versus multiple introductions in biological control. In: Brodeur, J. and Boivin, G. (eds.), Trophic and Guild Interactions in Biological Control. Springer, Dordrecht, NL. pp. 191-219.

Mumford, J.D. and Norton, G.A. 1984. Economics of decision making in pest management. Ann. Rev. Entomol. 29:157-174. 
Oliveira, L., Durao, A.C., Fontes, J., Roja, I.S. and Tavares, J. 2017. Potential of Trichogramma achaeae (Hym.: Trichogrammatidae) in biological bontrol of Tuta absoluta (Lep.: Gelechiidae) in Azorean greenhouse tomato crops. J. Econ. Entomol. 110:20102015.

Pedigo, L.P., Hutchins, S.H. and Higley, L.G. 1986. Economic injury levels in theory and practice. Ann. Rev. Entomol. 31:341-368.

Polaszek, A., Rugman-Jones, P.F., Stouthamer, R., HernandezSuarez, E., Cabello, T. and Pino, M. del. 2012. Molecular and morphological diagnoses of Canary Islands Trichogramma species for biocontrol of Chrysodeixis chalcites (Lep. Noctuidae) and Tuta absoluta (Lep. Gelechiidae). BioControl 57:21-35.

Poston, F.L., Pedigo, L.P. and Welch, S.M. 1983. Economic injury levels: reality and practicality. Bull. Entomol. Soc. Am. 29:49-53.

Price, P.W., Bouton, C.E., Gross, P., McPheron, B.A., Thompson, J.N. and Weis, A.E. 1980. Influence of plant on interactions between insect herbivores and natural enemies. Ann. Rev. Ecol. Syst. 11:41-65.

Rosenheim, J.A. and Harmon, J.P. 2006. The influence of intraguild predation on the suppression of a shared prey population: an empirical reassessment, In: Brodeur, J. and Boivin, G. (eds.), Trophic and Guild Interactions in Biological Control. Springer, Dordrecht, NL. pp. 1-20.

Ruppel, R.F. 1983. Cumulative insect-days as an index of crop protection. J. Econ. Entomol. 76:375-377.

Sanchez, J.A. 2008. Zoophytophagy in the plantbug Nesidiocoris tenuis. Agric. For. Entomol. 10:75-80.

Saphores, J.D.M. 2000. The economic threshold with a stochastic pest population: a real options approach. Amer. J. Agr. Econ. 82:541-555.
Shoemaker, C. 1973. Optimization of agricultural pest management III: results and extensions of a model. Math. Biosci. 18:1-22.

Smith, C.M. 2005. Plant Resistance to Arthropods: Molecular and Conventional Approaches. Springer, Dordrecht, NL.

Tang, S. and Cheke, R.A., 2008. Models for integrated pest control and their biological implications. Math. Biosci. 215:115-125.

Tang, S., Tang, G. and Cheke, R.A. 2010. Optimum timing of integrated pest management: modelling rates of pesticide applicacition and natural enemy releases. J. Theor. Biol. 264:623-638.

Varga, Z., Sebestyen, Z., Gamez, M., Cabello, T. and Attias, A. 2010. Models of applied population dynamics. Mech. Eng. Lett. 10:22-36.

Vila, E. and Cabello, T. 2014. Biosystems engineering applied to greenhouse pest control. In: Torres, I. and Guevara, R. (eds.), Biosystems Engineering: Biofactories for Food Production in the XXI Century. Springer, Berlin. pp. 99-128.

Vila, E., Parra, A., Beltran, D., Gallego, J.R., Fernandez, F.J. and Cabello, T. 2012. IPM strategies in tomato crops in Spanish greenhouses: Effects of cultivars and the integration of natural enemies. IOBC-WPRS Bull. 80:245-251.

Yano, E. 2005. Effects of intraguild predation and interspecific competition among biological control agents in augmentative biological control in greenhouses, In: Hoddle, M.S. (ed.), Second International Symposium on Biological Control of Arthropods, September 12-16, Davos, CH. USDA Forest Service (Publication FHTET-2005-08). pp. 523-530.

Received November 29, 2017 Revised March 30, 2018 Accepted April 13, 2018 